\title{
¿CÓMO INFORMARON LOS MEDIOS DE COMUNICACIÓN SOBRE LA INFLUENZA AH1N1 EN PERÚ?
}

\author{
Ada Palpan-Guerra1,a, César V. Munayco ${ }^{1, b}$
}

\begin{abstract}
RESUMEN
Se analiza las características de las noticias emitidas por los medios de comunicación del Perú (MC) sobre influenza AH1N1 en el 2013, para lo cual se revisaron diariamente los MC escritos, radio, televisión e Internet. Las noticias se clasificaron según encuadre, valoración (educativa, informativa y con elevada percepción del riesgo de contagio y muerte -NEPRCM) y alcance. Se realizó un análisis descriptivo de las principales variables del estudio. El encuadre de la noticias estuvo centrado en los casos de influenza (47,5\%) y las acciones del MINSA/otras instituciones $(29,0 \%)$. El mayor porcentaje de noticias fueron de carácter informativo (73,7\%), y solo el 7,5\% fueron NEPRCM; estas últimas fueron más frecuentes en los diarios (9,0\%) y televisión (9,4\%). Durante el 2013, los MC, en general, fueron responsables al momento de informar, aunque hubo algunos que difundieron noticias que podrían haber incrementado la percepción de riesgo en la población.
\end{abstract}

Palabras clave: Subtipo H1N1 del virus de la influenza A; Medios de comunicación; Perú (fuente: DeCS BIREME).

\section{HOW DID THE MEDIA REPORT ON THE AH1N1 INFLUENZA IN PERU?}

\begin{abstract}
We analyzed the characteristics of news issued by communication media (CM) in Peru on H1N1 influenza in 2013, for which written, radio, television and internet $\mathrm{CM}$ were reviewed daily. The news were classified according to framing, estimation (educational, informative and with high perception of risk of contagion and death) and scope. A descriptive analysis of the main variables of the study was made. The framing of the news was focused on influenza cases $(47.5 \%)$ and actions of the Ministry of Health and other institutions (29.0\%). The highest percentage of news was informative $(73.7 \%)$, and only $7.5 \%$ were news with high perception of risk of contagion and death; the latter was more frequent in newspapers $(9.0 \%)$ and television (9.4\%). During 2013, the CM, in general, was responsible at the time of reporting, although there were some that spread news that could have increased the perception of risk in the population.
\end{abstract}

Key words: Influenza A virus, H1N1 subtype; Communications media; Peru (source: MeSH NLM).

\section{INTRODUCCIÓN}

La Organización Mundial de la Salud (OMS) reconoce la importancia de los medios de comunicación (MC) durante una emergencia sanitaria, por lo que recomienda a los países, por ejemplo: "Establecer buenas relaciones con periodistas claves y otros canales de comunicación para familiarizarlos con la influenza y con asuntos relacionados a la pandemia", para facilitar la difusión de mensajes eficaces que informen, eduquen a la población y disminuyan la posibilidad que se generen mensajes inadecuados que generen alarma ${ }^{(1)}$.

Desde la perspectiva de la economía política crítica (2), se menciona que "Los medios comerciales no buscan la producción de mensajes con contenidos sociales o culturales, sino que se centra en aquellas que resultan más sensacionalistas, superfluas o perjudiciales". En este sentido, algunos estudios, muestran que las noticias alarmistas difundidas por la prensa podrían haber, por ejemplo, incrementado el uso de antibióticos en la población mayor de 16 años en Francia, o haber incrementado la preocupación por la posibilidad de infectarse durante la última pandemia ${ }^{(3,4)}$.

Si bien es cierto estamos en etapa pospandémica, el virus de la influenza continua circulando y es notificado por los servicios de salud a los sistemas de vigilancia centinela de influenza del país ${ }^{(5)}$. La presencia de este virus sigue generando preocupación en la población, la cual es alimentada por la frecuencia e intensidad de la difusión de noticias relacionadas con esta enfermedad ${ }^{(4,6)}$.

\footnotetext{
Dirección General de Epidemiología, Ministerio de Salud. Lima, Perú.

a Licenciada en Comunicación Social, ${ }^{\mathrm{b}}$ médico, magíster en Epidemiología y Salud Pública.

Recibido: : 30-09-14 Aprobado: 08-04-15
} 
Con el objetivo de analizar las características de las noticas emitidas por los MC sobre la influenza AH1N1 durante el 2013, se revisaron todas las noticias relacionadas a esta enfermedad que fueron publicadas en los MC de prensa escrita, televisiva, radial e Internet de cobertura nacional para determinar el encuadre, la valoración y el alcance de las noticias.

\section{EL ESTUDIO}

Se realizó una búsqueda diaria de todas las noticias relacionadas a la influenza que fueron publicadas en los MC de prensa escrita, televisiva, radial e Internet de cobertura nacional, entre el 9 de julio al 6 de septiembre de 2013. La búsqueda y el registro (encuadre, valoración y alcance) de las noticias fueron realizados por una comunicadora social.

Se revisaron las noticias publicadas por 22 diarios escritos: El Comercio, El Peruano, Correo, La República, Perú 21, Del País, Diario 16, El Chino, El Diario de Hoy, El Men, Ajá, El Popular, Trome, Expreso, Extra, Gestión, La Nación, La Primera, La Razón, Ojo, Publímetro y Sol de Oro. Asimismo, se evaluaron todas las ediciones periodísticas de cinco radiodifusoras: Radio Programas del Perú (RPP), Nacional, Capital, Exitosa y San Borja. Solo se incluyeron las notas periodísticas, obviando los titulares de cada edición.

Se evaluaron los espacios periodísticos de seis canales de televisión de señal abierta: América TV, Andina de Radiodifusión y Televisión (ATV), Frecuencia Latina, TV Perú, RBC y Panamericana TV, y cuatro de señal cerrada (cable): Radio Programas del Perú TV, ATV +, Canal N, y Willax. Además, se revisaron las notas sobre la influenza de 25 páginas web: Andina, Correo, Diario 16, El Comercio, Generación, El Peruano, Exitosa, El Popular, Expreso, Aeronoticias, Américatv, Trome, La Mula, La Razón, La República, Ojo, Panamericana, Perú 21, Peru.com, Radio Capital, Radio Nacional, RPP, Radio San Borja, Terra.com y Tuteve.

Las notas y portadas que informaban sobre la influenza se evaluaron individualmente, agrupando el titular, el cuerpo de la noticia (texto e imagen, audio y video), efectos/fondo musical y demás recursos informativos como una unidad de análisis.

El encuadre de la noticia se clasificó según la perspectiva de la agenda-setting ${ }^{(2)}$ en base a la agenda que proponen los MC. En este sentido, las notas periodísticas fueron clasificadas de acuerdo al eje principal de la noticia en: a). Casos de influenza; b). Desabastecimiento de vacunas; c). Casos y desabastecimiento de vacunas; d). Acciones del MINSA/otras instituciones; e). Medidas de prevención: recomendadas por especialistas en el tema; f). Medidas de prevención recomendadas por el medio de comunicación.

La valoración de la noticia se categorizó según lo descrito por Lasswell y Wright ${ }^{(2)}$, que estudian la comunicación de masas desde el marco de sus funciones, en: (1) Supervisión del entorno - circulación de noticias, a la que denominaremos informativa, y (2) Transmisión de cultura, a la que llamaremos educativa. Asimismo, se consideró la disfunción de la comunicación de masas de Charles R. Wright (3). Provocar pánico al informar sobre peligros, a la que denominaremos noticias con elevada percepción del riesgo de contagio y muerte (NEPRCM). Estas categorías se definieron de acuerdo a los siguientes criterios:

1. Noticia informativa: se informó del evento sin necesidad de contemplar textos, imágenes, audios y/o videos que generen alarma, pánico y/o terror en la población.

2. Noticia educativa: se informó sobre los síntomas de la enfermedad, información médica, y medidas de prevención y/o centros de consulta.

3. NEPRCM: si en más de tres oportunidades (texto y/o audio) se encontraron palabras equivalentes a mortal, alarma, pánico, letal, emergencia, peligroso, amenaza, terror, temida gripe, gripe de la muerte, víctima mortal, virus asesino y plaga. Asimismo, cuando el video/imagen muestre a una persona con mascarilla N95, por no ser una recomendación del Ministerio de Salud (MINSA), pacientes internados, intubados, personas llorando y/o rezando.

El alcance de la noticia se definió en función al número de departamentos que tuvieron más exposición mediática en los MC.

Se realizó un análisis de frecuencias relativas y porcentajes de las principales variables del estudio. Además, se calcularon las frecuencias de aparición del tipo de encuadre y valoración de la noticias por día para evaluar la evolución de estas variables durante el periodo de estudio.

\section{RESULTADOS}

Se recolectó un total de 1618 noticias durante el periodo de estudio. La Tabla 1, muestra que el mayor porcentaje de noticias correspondieron a MC televisivos $(36,0 \%)$ y diarios (32,3\%). Canal N (11,5\%), RPP (Radio y televisión) (16,3\%) generaron el mayor número de noticias. Las noticias, en su mayoría, se refirieron a 
Tabla 1. Características generales de los medios de comunicación y las noticias

\begin{tabular}{lcc}
\hline & $\mathrm{n}$ & $(\%)$ \\
\hline Tipo de medio de comunicación & & \\
\hline Televisión & 583 & $(36,0)$ \\
\hline Diario & 522 & $(32,3)$ \\
\hline Web & 357 & $(22,1)$ \\
\hline Radio & 156 & $(9,6)$ \\
\hline Principales medios de comunicación & & \\
\hline Canal N (televisión) & 186 & $(11,5)$ \\
\hline Radio Programas del Perú (radio) & 155 & $(9,6)$ \\
\hline Radio Programas del Perú (televisión) & 109 & $(6,7)$ \\
\hline El Comercio (diario/web) & 76 & $(4,7)$ \\
\hline La República (diario/web) & 71 & $(4,4)$ \\
\hline Correo (diario/web) & 71 & $(4,4)$ \\
\hline TV Perú (televisión) & 67 & $(4,1)$ \\
\hline Andina (web) & 59 & $(3,6)$ \\
\hline Perú 21 (diario/web) & 54 & $(3,3)$ \\
\hline Otros medios de comunicación & 770 & $(47,7)$ \\
\hline Alcance de la noticia & & \\
\hline Dos o más departamentos & 711 & $(43,9)$ \\
\hline Lima & 354 & $(21,9)$ \\
\hline Callao & 121 & $(7,5)$ \\
\hline Lambayeque & 69 & $(4,3)$ \\
\hline La Libertad & 62 & $(3,8)$ \\
\hline Áncash & 55 & $(3,4)$ \\
\hline Ica & 48 & $(3,0)$ \\
\hline Otros departamentos & 198 & $(12,2)$ \\
\hline Encuadre de la noticia & & \\
\hline Casos de influenza* & 769 & $(47,5)$ \\
\hline Acciones del Ministerio de Salud/otras instituciones & 470 & $(29,0)$ \\
\hline Desabastecimiento de vacunas & 189 & $(11,7)$ \\
\hline Casos de influenza y desabastecimiento de vacunas & 87 & $(5,4)$ \\
\hline Medidas de prevención recomendadas por & 70 & $(4,3)$ \\
\hline especialistas en el tema & 33 & $(2,0)$ \\
\hline Medidas de prevención recomendadas por el medio \\
de comunicación & & \\
Valoración de la noticia & 1192 & $(73,7)$ \\
\hline Noticia informativa & 222 & $(13,7)$ \\
\hline Noticia informativa y educativa & 121 & $(7,5)$ \\
\hline Noticia con elevada percepción del riesgo de & 47 & $(2,9)$ \\
contagio/muerte & 36 & $(2,2)$ \\
\hline Nota educativa & & \\
\hline Noticia con elevada percepción del riesgo de & \\
contagio/muerte y educativa & & \\
\hline
\end{tabular}

* Incluye fallecidos por influenza
Las noticias sobre casos de influenza fueron más frecuentes en diarios $(49,0 \%)$ y televisión $(52,5 \%)$ que en la radio $(34,0 \%)$ y la web $(43,1 \%)$, y las noticias sobre las acciones del MINSA/otras instituciones fueron más frecuentes en la radio $(34,6 \%)$ y en la web $(35,9 \%)$ que en los diarios $(30,3 \%)$ y la televisión $(22,3 \%)$. Las noticias relacionadas al desabastecimiento de vacunas fueron más frecuentes en la radio $(13,5 \%)$ y en la televisión $(14,8 \%)$ que en los diarios $(9,2 \%)$ y la web $(9,5 \%)$. En general, todos los MC difundieron con mayor frecuencia noticias informativas (diario: $74,2 \%$, radio: $77,6 \%$, televisión: $72 \%$, y web: $73,9 \%$ ) que NEPRCM (diarios [9,0\%], televisión $[9,4 \%]$, radio [2,6\%] y web [4,2\%]) (información no incluida).

El encuadre de la noticia cambió diariamente, pero predominaron las noticias referidas a los casos de influenza, a las acciones del MINSA/otras instituciones $(76,5 \%)$. El mayor número de noticias se concentró entre el 15 y 24 de julio, con un pequeño incremento en número de noticias entre el 26 y 30 de agosto (Figura 1).

Las noticias sobre los casos de influenza se presentaron casi todos los días, y entre el 13 de julio y 7 de agosto. Las noticias sobre las acciones del MINSA/otras instituciones, estuvieron presentes todos los días y en mayor frecuencia que las otras noticias. Las noticias sobre el desabastecimiento de vacunas predominaron entre el 18 y 26 de julio (Figura 1).

Las noticias informativas predominaron durante el 2013, pero fueron más frecuentes entre el 16 y 26 de julio. En cambio las NEPRCM se presentaron con menor frecuencia y entre el 15 y 26 de julio (Figura 2).

Entre las principales portadas de los diarios con NEPRCM tenemos, por ejemplo, las relacionadas al

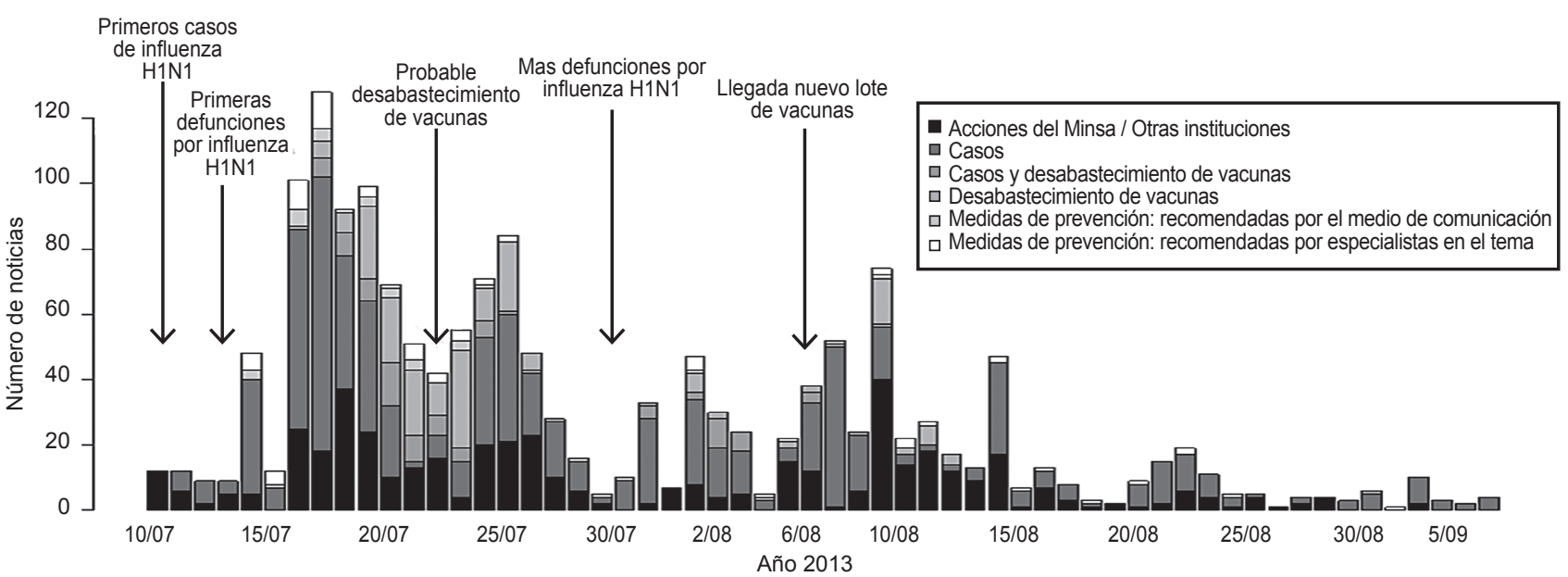

Figura 1. Evolución del encuadre de las noticias difundidas por los medios de comunicación: radio, diario, televisión e Internet 


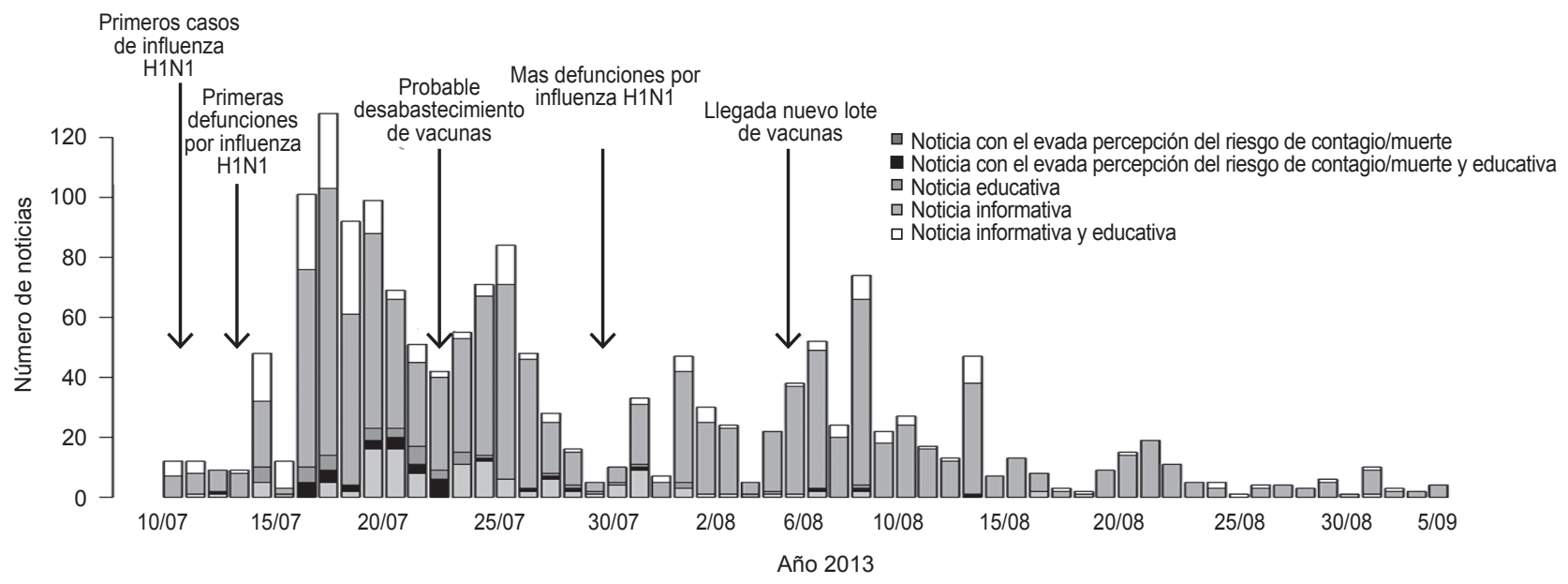

Figura 2. Evolución de la valoración de las noticias difundidas por los medios de comunicación: radio, diario, televisión e Internet

peligro que representa la influenza (per se): "gripe de la muerte", jalerta roja!", "pánico por la gripe A H1N1", "virus asesino", "se viene la plaga", etc. Algunas portadas se refirieron a las acciones del Ministerio de Salud, por ejemplo: "la gripe no hace huelga", "clínicas y hospitales sin vacunas A H1N1", "mueren y no hay vacunas", etc.

\section{DISCUSIÓN}

Este estudio muestra, que durante el 2013, el encuadre de la noticia se enfocó en los casos de influenza, en las acciones del MINSA/otras instituciones y el desabastecimiento de vacunas. La valoración de la noticia mostró que estas fueron principalmente noticias informativas, con un pequeño porcentaje de NEPRCM, y fueron los diarios y la televisión los que tuvieron mayor proporción de NEPRCM. Las limitaciones de este estudio están relacionadas principalmente con la cobertura de las noticias, ya que solo se accedió a MC de alcance nacional.

Durante la última pandemia de influenza, el comportamiento de los MC fue heterogéneo, en algunos países el contenido de las noticias fue alarmista ${ }^{(4,7,8)}$, en otros fue moderado y enfocado en informar y educar a la población ${ }^{(6)}$. En el Perú, durante el 2013, los medios de comunicación informaron responsablemente, porque emitieron principalmente contenidos informativos $y$ educativos que NEPRCM. Esto probablemente se debió al trabajo realizado por el MINSA, con los medios de prensa, durante la última pandemia, donde se desplegaron esfuerzos por acercarse a los MC y, sobre todo, considerarlos como aliados estratégicos ${ }^{(9)}$; ya que los $\mathrm{MC}$ que registraron el mayor porcentaje de noticias - Canal N, RPP, El Comercio-, se les considera entre los medios más responsables al momento de informar.
A pesar de que en general los MC fueron responsables al informar, hubo algunos que publicaron portadas con NEPRCM cuando aparecieron los primeros casos o muertes por influenza, esto último podría haber elevado la percepción de riesgo de la población, generando una mayor demanda en los servicios de salud, principalmente vacunas. Esto se observó durante la última pandemia de influenza, donde el mayor número de noticias, entre ellas las alarmistas, se dieron durante las primeras semanas, para luego perder el interés de los MC ${ }^{(4)}$.

Durante la última pandemia de influenza, por ejemplo en México, España y EE. UU., las portadas de los diarios con NEPRCM publicaron mensajes relacionados con 1). La severidad de la pandemia: "un catarro que acabó en un ataúd"; “¿está también Obama en peligro?”; "el temor a una mutación diabólica”, etc.; 2). Resaltar la inacción de las autoridades sanitarias: "¿cuánto vale una mascarilla?"; "dificultades para crear la vacuna"; "el extraño caso de la caída de muertes en México", etc. . $^{(8,7,10)}$. Las portadas de los diarios de nuestro país, presentaron similares mensajes: 1). Severidad de la pandemia: "gripe de la muerte"; jalerta roja!"; "pánico por la gripe AH1N1"; "se viene la plaga", etc. 2). Inacción de la autoridades sanitarias: "la gripe no hace huelga"; "clínicas y hospitales sin vacunas A H1N1"; "mueren y no hay vacunas", etc.

Al igual que en otros países ${ }^{(7,10)}$, los contenidos de las noticias estuvieron relacionados principalmente a la ocurrencia de casos de influenza, a las acciones del MINSA, y el desabastecimiento de vacunas. Es importante resaltar que el mayor volumen de noticias sobre la influenza ocurrió en la televisión y en los diarios, que son justamente los MC con mayor audiencia en el país.

Este estudio resalta el rol de los MC en la difusión de la información sanitaria, los cuales pueden informar 
o desinformar a la población, como algunos MC afortunadamente unos cuantos - que presentaron NEPRCM durante la temporada de influenza del 2013 como si estuviéramos aún en la fase pandémica de influenza, lo que podría haber ocasionado una sobrerreacción de las autoridades sanitarias y la población.

Por otro lado, la gran mayoría de medios tuvo un comportamiento responsable, informando sin sensacionalismo, por este motivo es importante que el MINSA continúe trabajando estrechamente con los $\mathrm{MC}$, con la finalidad de establecer una comunicación de riesgos adecuada, que ayude a orientar el comportamiento de la población. Para ello, es vital forjar alianzas con los MC para incluir en su agenda informativa temas relacionados con los riesgos y medidas para proteger la salud de la población.
Agradecimientos: a la Dirección General de Epidemiología, por el apoyo incondicional a esta investigación al brindar las facilidades del caso para realizarla.

Contribuciones de autoría: todos los autores participaron en la concepción y diseño del estudio. AP participó en la recolección de datos. CM participó en el análisis e interpretación de datos, AP y CM participaron en la redacción del manuscrito. Todos los autores participaron en la revisión crítica del manuscrito y aprobaron su versión final.

Financiamiento: autofinanciado.

Conflictos de interés: los autores declaran no tener conflictos de interés en la publicación de este artículo

Renuncia de responsabilidad: los contenidos de este manuscrito solamente son responsabilidad de los autores y no necesariamente representan la opinión oficial de la Dirección General de Epidemiologia del Ministerio de Salud.

\section{REFERENCIAS BIBLIOGRÁFICAS}

1. Organización Mundial de la Salud. Preparación y respuesta ante una pandemia de influenza [Internet]. Ginebra, Suiza: OMS; 2009 [citado el 02 de junio de 2014]. Disponible en: http://www.who.int/csr/swine_flu/ Preparacion_Pand_ESP.pdf

2. Lozano-Rendón J. Teoría e investigación de la comunicación de masas. Segunda. México: Longman de México Editores S.A. de C.V.; 2007.

3. Bernier A, Ligier C, Guillemot D, Watier L. Did media attention of the 2009 A(H1N1) influenza epidemic increase outpatient antibiotic use in France?: A time-series analysis. PLoS One. 2013 Jul 24;8(7):e69075. doi: 10.1371/journal.pone.0069075.

4. Mesch GS, Schwirian KP, Kolobov T. Attention to the media and worry over becoming infected: the case of the Swine Flu (H1N1) Epidemic of 2009. Sociol Health
Illn. $2013 \quad$ Feb;35(2):32531. doi: $10.1111 / \mathrm{j} .1467$ 9566.2012.01500.x.

5. Goméz Benavides J. Incremento de la circulación de virus de influenza A(H1N1)pdm09 en Lima Metropolitana y el Callao. Bol Epidemiol (Lima). 2013;22(28):608-9.

6. Hilton S, Hunt K. UK newspapers' representations of the 2009-10 outbreak of swine flu: one health scare not over-hyped by the media? J Epidemiol Community Health. 2011 Oct;65(10):941-6. doi: 10.1136/ jech.2010.119875.

7. Camacho Markina I. La "gripe A", en la prensa española. Rev Lat Comun Soc. 2009;12(64):827-43. doi: 10.4185/ RLCS-64-2009-865-827-843

8. Coronado Robles R, Catalán Matamoros D, Martínez González E. La gripe $\mathrm{A}(\mathrm{H} 1 \mathrm{~N} 1)$ en prensa. Rev Esp Comun Sal. 2011;2(1):32-45.
9. Ministerio de Salud del Perú. Plan Nacional de Preparación y Respuesta frente a una potencial pandemia de Influenza [Internet]. Lima, Perú: Ministerio de Salud del Perú; 2006 [citado el 02 de junio de 2014]. Disponible en: http://www.dge.gob. pe/aviar/PDF/Plan_Influenza_Peru. pdf

10. González GDCG, Hoyos JRC, Méndez MGC. Las metáforas de la influenza humana A (H1N1) en México: el escenario nacional al descubierto. Una aproximación a través de la prensa mexicana. Comun Soc. 2011;(16):105-32.

Correspondencia: Ada Palpán Guerra

Dirección: Avenida Daniel Olaechea 199.

Lima 11.

Correoelectrónico:apalpan@dge.gob.pe 